Revista de Economia Política, vol. 33, no 3 (132), pp. 446-462, julho-setembro/2013

\title{
A complexidade e o construtivismo na economia
}

\author{
ARNALDO MAUERBERG JUNIOR*
}

Complexity and constructivism in economics. This paper attempts to show and summarize the concept of rules, order and complexity introduced around the mid-twentieth century by Friedrich August von Hayek. It also attempts to create a current parallel between those concepts and the field of complexity economics. At the time of his writings, the author sought to present arguments against the Cartesian rationality. Nowadays, the concepts presented by him could also serve as arguments against the way of thought used in mainstream microeconomics. A debate can now be seen between the mainstream microeconomics and the authors of the complexity theory applied to the economy, which can be understood as explanations guided by generic assumptions versus natural explanations guided in a computational approach.

Keywords: Social behavior; Hayek; complexity; mainstream microeconomics.

JEL Classification: B41; B52; B53; D03; D79; D89.

\section{INTRODUÇÃO}

Atualmente a microeconomia neoclássica vem sendo criticada pela adoção de determinadas hipóteses, entre elas a que trata os agentes como seres racionais com plena capacidade para computar informações, e também pela sua suposição a respeito do atomismo ${ }^{1}$. Existem críticas também contra alguns de seus resultados referentes ao equilíbrio geral, como a sua multiplicação além de sua incapacidade de ser atingível em tempo razoável. Neste último ponto, Epstein e Hammond (2006) afirmam que deve ser questionada a suposição de que a análise de equilíbrio para as ciências sociais tem valor explanatório, e que, caso se insista em uma defesa deste

\footnotetext{
* Mestre em Economia pela FCLAR/UNESP e Doutorando em Administração Pública e Governo pela EAESP/FGV. E-mail: arnaldomauerberg@hotmail.com. Submetido: 15/maio/2012; Aprovado: 26/Outubro/2012/

${ }^{1}$ Para uma explanação precisa a respeito das principais hipóteses utilizadas pela microeconomia neoclássica o leitor pode consultar Mas-Colell, Whinston and Green (1995).
} 
tipo de análise, deve ser demonstrado que o equilíbrio defendido será atingido em tempo razoável pelos próprios agentes, fazendo-se uso de regras razoáveis.

Uma das fontes destas críticas é a ideia de complexidade em economia, entendendo como sistema complexo aquele no qual uma de suas partes influencia as outras que também estão envolvidas no mesmo sistema. O campo da economia e complexidade vem propondo teorias ao longo dos anos, olhando o fenômeno fora do equilíbrio. Nesta abordagem os agentes econômicos ajustam continuamente seu comportamento. Pode-se interpretar cada caso distintamente abrindo mão de modelos genérico-analíticos adotando-se para a análise uma abordagem de cunho computacional, ampliando assim o escopo do que pode ser teorizado, captando as relações entre os fenômenos e não sua constituição. Prado (2011) mostra que estruturas homogêneas não são comuns, e que a crescente complexidade dos fenômenos, dada hierarquicamente, deve ser considerada. Segundo Arthur (2005), neste sentido, a complexidade vem a ser um esforço para analisar o funcionamento dos sistemas descentralizados e organizados compostos por um número muito grande de agentes individuais. Para Foley (2007), as principais características dos sistemas complexos são: adaptabilidade, auto-organização e funcionamento de modo não equilibrado. Em Prado (2006) encontram-se indícios de que uma noção de sistemas complexos pode ser observada já nos escritos dos economistas clássicos como Smith, Malthus, Ricardo e Marx.

Uma análise mais profunda sobre certas regras que moldam e traçam a trajetória de dados fenômenos é um dos objetivos deste trabalho, apresentar ao leitor a ideia de complexidade expressa por Friedrich August von Hayek, um dos primeiros a fazer uso desta temática na economia, apresentando os conceitos de ordem, regras e organização de sistemas. Busca-se sintetizar e esquematizar as principais ideias daquele autor, interligando-as com as contribuições posteriores de outros sobre seus trabalhos no que diz respeito ao campo da economia e complexidade, uma vez que um dos objetivos deste trabalho é também apresentar o caráter contemporâneo da contribuição de Hayek "adaptada" pelos complexistas para a atual crítica ao mainstream econômico. Para tanto a metodologia empregada aqui é uma revisão de literatura sobre o tema, condensando os principais conceitos e considerações.

Cabe a ressalva de que existem duas opiniões distintas a respeito da contribuição de Hayek para o campo da complexidade. Entre estas distintas visões podemos citar: Kilpatrick (2001), que afirma que existem diferenças entre Hayek e os atuais complexistas, e Vaughn (1999), que acredita que a nova geração de estudos a respeito da complexidade está intrinsecamente ligada aos estudos hayekianos. Este artigo adota como premissa a ideia de que os atuais estudos sobre complexidade são inspirados por Hayek, seguindo assim a linha proposta por Vaughn (1999). Mas não renegando as valiosas contribuições oferecidas pela primeira linha, que serão expostas sempre que apresentarem pertinência à análise.

Além de apresentar as principais contribuições daquele economista austríaco ao campo da complexidade, o trabalho também almeja traçar paralelos entre sua teoria sobre comportamento social, basicamente expressa aqui pelos conceitos de regras e ordens, com as atuais premissas da microeconomia neoclássica que, como 
será exposta ao longo do trabalho, supõe-se seja fruto do racionalismo construtivista. Para isto também serão feitas considerações a respeito deste último.

Vale o comentário de que a intenção é apresentar com o adequado grau de profundidade as ideias alternativas ao mainstream tratadas pela abordagem hayekiana e suas aplicações à economia como método de pesquisa e explanação, sempre que possível, traçando um paralelo entre a crítica feita por Hayek à planificação socialista e a atual crítica dos estudiosos atuais contra as hipótese que fundamentam a microeconomia neoclássica. Nota-se que o antigo debate travado por Hayek contra as ideias de uma planificação do sistema econômico (características, por exemplo, do estalinismo) fundamentadas nos conceitos de regras, ordem e complexidade podem ser traduzidas para o debate atual entre microeconomistas neoclássicos e complexistas².

O trabalho possui relevância ao sintetizar uma série de pesquisas apresentando a gênese de um campo de estudos em economia (a complexidade) que vêm aumentando seu papel na academia, com seu contraponto à base de apoio da teoria mainstream. Sobre o aumento de importância do campo da complexidade, Hahn (1991) afirma que a teorização do tipo pura na economia se tornará menos apreciável e menos possível em um futuro não tão distante, disto supõe-se que exista um possível debate "microeconomia neoclássica (nas palavra de Hahn, teorização do tipo pura) versus complexidade". Assim, diferenciar a existência ideal (análise teórica) da existência concreta (análise complexa), como o proposto por Epstein (2006) torna-se um procedimento fundamental em análises do tipo.

Em um contraponto ao proposto por Hahn, Paulani (2010) em um trabalho que busca investigar a manutenção e hegemonia do mainstream econômico atual não apresenta um panorama favorável a uma possível troca de paradigma. Para ela, mesmo com todas as dúvidas e provas levantadas pelos opositores da escola neoclássica e de declarações não tão favoráveis por parte até dos principais expoentes deste pensamento ${ }^{3}$, a corrente se mantém quando uma nova geração de teóricos é produzida pela própria teoria ${ }^{4}$. As duas opiniões aqui refletidas, como era de esperar, mostram que não existe um consenso a respeito da manutenção do paradigma ou de sua substituição por outro. Fato é que, mesmo com a doutrinação

\footnotetext{
${ }^{2}$ Mesmo assim, será exposto mais adiante que o próprio Hayek já tecia seus comentários a respeito da Teoria do Equilíbrio Geral Walrasiano.

${ }^{3}$ Caso de Gérard Debreu que, na cerimônia de entrega de seu Nobel em 1983, afirmou que não era capaz de tecer comentários sobre política econômica pois apenas elaborava modelos teóricos.

${ }^{4}$ Ainda sobre este assunto, Prado (2001) mostra que a introdução do estudo da economia "moderna" no Brasil foi amplamente apoiado sobre doutrinas ortodoxas americanas, sugerindo que a estratégia desta implantação fora bem-sucedida acompanhando-se as publicações de duas importantes revistas nacionais, a Revista Brasileira de Economia e a Estudos Econômicos, com uma primeira leva de estudos ortodoxos realizados por estrangeiros, e uma segunda fase com estudos de mesmo cunho (principalmente no caso da $R B E$ ) porém nacionais, oferecendo indícios de que os esforços de formar uma classe de economistas brasileiros ortodoxos pode ter dado certo, uma vez que estes estariam ocupando o lugar daqueles nas publicações citadas.
} 
solidificada do mainstream, novas vertentes metodológicas surgem na economia conquistando adeptos em diversos centros.

Ressalta-se ainda que à época dos escritos de Hayek pode ser constatado que uma de suas intenções era atacar o modelo planificado baseado em um racionalismo construtivista ou cartesiano, utilizando para isso conceitos de regras, ordem e complexidade, afirmando que seria impossível a coordenação de uma sociedade por um único agente, no caso o Estado. Este trabalho admite também que as críticas de Hayek à racionalidade cartesiana podem ser incorporadas às hipóteses de racionalidade perfeita do mainstream econômico. Segundo Ganem (2006), Hayek critica o racionalismo equilibrante neoclássico ao afirmar que o homem não é fruto do plano, e sim seguidor de regras. Para Ganem (2012), a crítica de Hayek foi concentrada contra o estalinismo. Mas, como defende Paulani (1999), Hayek também tece críticas ao mainstream econômico quando contraria a suposição neoclássica de homogeneizar os indivíduos em átomos de comportamento idêntico e previsível, assim, tal teoria estaria equivocadamente ignorando características únicas que apenas um indivíduo é capaz de possuir, e que pode, de alguma maneira, interferir no todo, ou seja, o correto para ele seria explicar o todo com base nas ações individuais.

Feita a introdução, o trabalho se estrutura da seguinte forma: após esta seção, na segunda seção serão apresentados conceitos metodológicos expressos por Hayek sobre regras, ordem e complexidade, assim como também suas críticas contra o racionalismo cartesiano, além de uma breve explicação acerca do construtivismo.

$\mathrm{Na}$ terceira seção será exposta a aplicação econômica dos conceitos apresentados na seção precedente com a análise conjunta de demais teóricos a respeito do assunto. Pretende-se nessa seção que sejam apresentados os contrapontos entre as formulações de Hayek e as proposições em defesa da planificação, assim como o atual debate entre os complexistas e o maisntream microeconômico.

$\mathrm{Na}$ quarta e última seção será feita a conclusão, com as devidas considerações a respeito do tema tratado pelo trabalho.

\section{RACIONALIDADE, REGRAS, ORDEM E COMPLEXIDADE}

Na presente seção a intenção é mostrar, principalmente, ao leitor os conceitos e ideias de Hayek sobre regras, ordem e complexidade, além de suas críticas ao racionalismo cartesiano.

Neste contexto pode-se admitir a existência de duas formas de explanação, uma que exige que tudo seja resultado de uma mente pensante e outra que admite a existência de processos incompreensíveis à mente humana.

René Descartes é o responsável pelo desenvolvimento da primeira forma de explicação supracitada denominada racionalismo cartesiano ou construtivista. Esta visão teórica pode ser interpretada grosso modo da seguinte forma: tudo o que não pode ser deduzido logicamente de premissas explícitas deve ser desconsiderado. 
Sendo que, neste método, dedução lógica era a ação racional ${ }^{5}$. Nesta visão todas as realizações humanas são o resultado de seu raciocínio única e exclusivamente. Desta forma observa-se a necessidade de um conhecimento total dos fatos relevantes para cada situação, suportado pela crença dos racionalistas no avanço da ciência. No racionalismo cartesiano a abstração não é considerada, e as teorias vinculadas a esta linha de pensamento sugerem que processos sociais só servem ao homem se puderem ser controlados pela razão humana, fazendo com que os construtivistas rejeitem suas normas quando estas não podem ser justificadas racionalmente. Segundo Hayek ([1973] 1985), quando o racionalismo construtivista se empenha em submeter tudo ao controle racional, preferindo o concreto e se negando a admitir normas ou regras abstratas, este passa a andar muito próximo do irracionalismo. Além do mainstream microeconômico, o racionalismo cartesiano pode ser observado por exemplo nas ideias de Bentham ([1781] 1988), com seu conceito de utilitarismo.

A forma de explanação na qual Hayek se enquadra vai contra o racionalismo cartesiano e pode ser chamada de "anti-racionalismo" ${ }^{\circ}$ ou racionalismo evolucionista e é defendida por Adam Smith, John Locke, Bernard Mandeville, David Hume, Josiah Tucker, Adam Ferguson, Edmund Burke, Aléxis de Tocqueville, Lord Acton, entre outros. Trata-se de uma teoria que olha para os determinantes da vida social do homem. Segundo Ganem (2012), as afirmações de Hayek partem de um indivíduo ignorante, em um mundo inalcançável pelo conhecimento na sua totalidade. Aqui a abstração e ausência de total conhecimento são conceitos fundamentais, afirmando que o agente é ignorante à maioria dos fatos que determinam suas ações, e que necessitam da ajuda de processos dos quais ele não tem consciência para atingir a máxima eficácia da razão ${ }^{7}$. De acordo com Hayek,

o erro característico dos racionalistas construtivistas (...) é tenderem a fundamentar a sua argumentação no que foi chamado de ilusão sinótica, ou seja, na ficção de que todos os fatos relevantes são conhecidos por alguma mente e que é possível construir, a partir desse conhecimento dos fatos particulares, uma ordem social desejável. ([1973] 1985, p. 9, grifo no original)

Ainda em Hayek ([1946] 1948), os agentes devem ser submissos a princípios gerais porque não têm todo o conhecimento para orientar suas atitudes, não são oniscientes, sendo que a única forma que o indivíduo tem para obter a liberdade é

\footnotetext{
${ }^{5}$ Além da economia, a ação racional como meio de explanação vem crescendo em outras disciplinas, entre elas a ciência política, como observado em Shesple (2010).

${ }^{6} \mathrm{O}$ termo é empregado aqui única e exclusivamente para mostrar a divergência desta linha de pensamento em relação ao construtivismo, não afirmando portanto que tal linha seja fundada em ações irracionais.

${ }^{7}$ Razão aqui não no sentido construtivista.
} 
através de regras ou normas gerais que limitam a esfera de decisão do cidadão. Aqui entra o conceito de regras, que será, então, mais bem apresentado.

Contrariando o racionalismo cartesiano, Hayek acredita que o homem segue regras que não é capaz nem de descrever. No arcabouço hayekiano o termo regra pode ser assumido como uma afirmação pela qual a regularidade do comportamento dos indivíduos pode ser descrita. As regras nem sempre podem ser plenamente explicáveis. Assim, como explicar, por exemplo, o fato de uma criança falar um idioma corretamente antes mesmo de entrar na escola? Tal regra é uma regra de percepção. Logo, nota-se que o conhecimento dos agentes não é perfeito como afirmam os cartesianos, como eles próprios defendem que se não pode ser explicado matematicamente não é então de serventia. Seria então desnecessário o uso do idioma?

As regras podem ser naturais (transmitidas geneticamente) ou de aprendizado (transmitidas culturalmente), sendo estas últimas mais flexíveis, como em uma sociedade onde se nota certa tolerância com os jovens em aprendizado e uma certa imitação da conduta dos mais velhos, mas vale notar que, antes da imitação, a identificação das regras já deve ter sido realizada, sendo que o fenômeno de sua percepção é fundamental para que regras de aprendizado possam se perpetuar, sendo que o fenômeno de descrevê-las (no sentido construtivista) não se faz assim necessário. As regras fornecem um bom guia para o convívio em sociedade, sendo que algumas delas acabam por impor certos limites, por exemplo afastando os agentes de situações perigosas (não é necessário ser atacado por uma onça para saber as consequências de seu ataque).

Com relação às regras naturais, pode-se notar certos comportamentos como o de um recém-nascido em reconhecer prontamente sua mãe, este fato pode ser reconhecido, mas dificilmente explicado matematicamente. Com relação à explanação das regras, Hayek ([1963] 1967) conclui que afirmar ou informar todas as regras que guiam o comportamento humano é praticamente impossível, o que implica uma limitação do conhecimento, fazendo com que nem sempre seja possível explicar completamente a mente humana.

Sobre o que pauta o comportamento dos agentes, Chaumont-Chancelier (1999) afirma que no arcabouço hayekiano o agente não é tratado como um seguidor de regras, mas como um seguidor de metas, e que as regras o ajudam a atingir suas metas.

Sobre esta questão, Paulani (1996) procura mostrar que a posição de Hayek aponta para a condição contraditória do indivíduo, o conhecimento individual e exclusivo dos agentes origina-se nas regras, que são fundamentalmente constituídas de maneira social. Desta maneira, o indivíduo, ao seguir regras, age de maneira pautada pelo social no qual está inserido, minando até certo ponto a autonomia dos autores como tratada por Hayek.

Outro conceito importante relacionado ao tema deste trabalho é o conceito de ordem. $\mathrm{O}$ agir individual resulta em uma ordem de ações, como por exemplo os diversos movimentos individuais do corpo humano que têm por resultado uma ordem. 
Deve-se aqui atentar para o fato de que as regras já citadas e a ordem resultante não são a mesma coisa. Hayek argumenta que a distinção entre uma ordem e uma regra pode ser suportada pelos seguintes fatos: uma ordem observada não necessariamente implica que as regras inerentes a esta ordem sejam também observadas, o interessante na preservação do grupo é o agregado de ordens, e não a regularidade individual, a manutenção da ordem é uma regra abstrata, pois o agregado de ações individuais que resulta em uma ordem nem sempre é consciente, e que o todo pode ser ordenado independentemente de uma ação individual.

Para Vaughn (1999), ordem espontânea e sistema auto-organizado são sinônimos, afirmando ainda que o interesse de Hayek por biologia e seu envolvimento com a teoria cognitiva levou os atuais estudiosos da complexidade a buscar conhecimento na mesma literatura explorada por ele para o desenvolvimento atual de suas ideias. Prado (2008) não concorda com tamanha espontaneidade nos fenômenos, para ele Hayek e sua teoria encontram-se dentro do capitalismo e buscam meios de explicar seu funcionamento de uma maneira agradável, contentando-se com o que é fruto deste sistema. Prado continua ao afirmar que uma posição observadora passiva do agente, que nada poderia fazer, pois encontra-se em um sistema onde os acontecimentos seriam em última análise fruto de processos involuntários, é incorreta e defende que a dialética de Marx se aplica melhor ao entendimento desta questão ao propor que a evolução dos sistemas sociais não são fruto de eclosões involuntárias como na biologia, mas das interações, embates e contradições dos agentes, que atuando ativamente nas decisões acabam por encontrar a síntese do processo em questão. Por fim, vale o comentário de que, sob esta ótica, uma vez posicionado dentro de seu objeto de análise (o capitalismo) e na intenção de explicá-lo de modo a obter o convencimento e a aceitação de que se trata do melhor sistema econômico, Hayek não ultrapassa o nível da ciência positiva que se contenta em entender as relações externas entre os fenômenos de modo a fornecer explicações posteriores para sua manutenção.

De volta à explanação, no arcabouço hayekiano existem dois tipos de ordem, as do tipo táxis e as do tipo kosmos (Angeli, 2007). As primeiras são exógenas ou artificiais, simples e geralmente servem ao seu criador, enquanto as últimas são autogeradoras ou endógenas, possuem um elevado grau de abstração, não são criadas, logo não são propositadas, estas últimas são as de maior interesse no campo da complexidade e da economia.

Pode-se observar que certas regras individuais levam a uma ordem como no caso da marcha de uma tropa, mas é enganoso supor que a observação de um determinado evento sempre levará ao reconhecimento de uma ordem. Assim, são compreendidas certas ordens que não são passíveis de explicação. Entretanto, como diz Hayek,

o fato de reconhecermos ordens que não somos capazes de descrever não significa que tal percepção pode servir legitimamente como elemento de explanação científica. (...) Tem que se considerar que é totalmente consis- 
tente, (...) negar que este "todo" que é compreendido intuitivamente pelos cientistas pode figurar em suas explanações. ([1963] 1967, pp. 54-55)

Sobre o nível de influência ao qual uma ordem está sujeita, tem-se que uma ordem pode sofrer influência apenas em seu caráter geral, mas não em seus detalhes.

Retomando o raciocínio anterior de que o interessante à análise é o agregado de ordens, e não a regularidade individual, e que a manutenção de uma dada ordem é uma regra abstrata, uma vez que o agregado de ações individuais resultando em uma ordem nem sempre é consciente, pode ser afirmado que uma certa ordem resultante não é apenas a soma de eventos individuais, existe uma conexão entre as partes que não pode ser ignorada. Assim, uma teoria que procure descobrir as "leis do universo" encontra certa dificuldade quando a análise é feita em estruturas que estão interligadas entre si, ou seja, não podem ser reduzidas a regularidades das partes isoladas, porque estas interagem com o todo e com o ambiente. Tais características são observadas em sistemas complexos. Nestes sistemas pode ser observada também uma dinâmica não linear e operante fora do equilíbrio, com agentes heterogêneos dotados de racionalidade limitada, vinculados por estruturas e instituições sociais, sendo os efeitos macroeconômicos resultados de ações microeconômicas (Prado, 2006).

A complexidade reside na interação de regras entre vários indivíduos e na ordem resultante desta interação. Os fenômenos simples são os naturais ou físicos, ou seja, os que podem ser simplesmente formulados, enquanto a complexidade se encontra nos fenômenos sociais, da mente e da vida onde uma formulação precisa é praticamente impossível. Quanto mais difícil for a formulação, maior será o grau de complexidade do fenômeno em questão. Uma análise social é inerentemente complexa, uma vez que as sociedades são compostas por elementos que por si sós já são complexos.

No campo da complexidade a ausência de fatos concretos inerentes à explanação é um fator-chave, pois trata-se da interação de regras de conduta muitas vezes indescritíveis, que podem gerar uma ordem igualmente indescritível.

Complexidade leva ao fato de que os cientistas sociais não podem fazer previsões, e sim explicações. Esta afirmação se aproxima de certo modo da proposta por Mises (1949), quando este afirma que o futuro é incerto e as ciências naturais não podem prevê-lo, assim como também não podem prever as consequências de determinados atos humanos. A impossibilidade de previsão é mais clara em duas circunstâncias: a primeira diz respeito a quando os fenômenos naturais são desconhecidos, e a segunda, quando se trata da decorrência de atos oriundos da escolha humana ${ }^{8}$.

De acordo com Barbieri (2001), a distinção entre Mises e Hayek reside no fato de o primeiro considerar a ação proposital do homem, que implica derivações

\footnotetext{
${ }^{8}$ Apenas a título de conhecimento, a incerteza é um conceito-chave também para o pensamento pósKeynesiano, na existência de incerteza o cálculo probabilístico é impossível, baseando-se na crença de que nem todos os eventos econômicos são baseados em processos estocásticos (Davidson, 1988).
} 
lógicas, tornando verdadeira a teoria econômica, enquanto o segundo admite que os resultados econômicos não residem de axiomas irrefutáveis, sendo os teoremas não válidos a priori, variando de acordo com os postulados sobre o conhecimento dos agentes.

Segundo Chaumont-Chancelier (1999), para se observar coerência em Hayek deve-se atentar para a complexidade. A complexidade é a ligação entre Hayek, o economista do mercado, e Hayek, o teórico da evolução cultural.

Arthur (1999), se aproximando a um conceito hayekiano ${ }^{9}$, define um sistema complexo como aquele onde múltiplos elementos se adaptam ou reagem a regras que estes próprios sistemas criaram.

A principal dificuldade em complexidade vem da necessidade de averiguar todos os dados que determinam uma manifestação do fenômeno estudado. Quando a relação entre as partes é importante para o estudo em questão, a estatística não pode fornecer ajuda, pois não é capaz de captar a interdependência dos elementos, porém ela pode ser de alguma utilidade quando o foco é a complexidade e não os elementos que a formam.

Hayek ([1964] 1967) afirma que, considerando que todos os parâmetros de um sistema de equações que descrevem uma estrutura complexa estão constantes, pode se supor então uma dependência entre eles (uma lei), e considerar a mudança de um como causa e do outro como efeito, mas tal lei mudaria sempre quando um dos parâmetros apresentar mudança, e seria válida apenas naquele cenário. Fenômenos complexos não obedecem a uma única lei. Geralmente a descoberta de uma relação entre duas variáveis é indutivista, no caso da complexidade, cada teórico deve ter sua própria teoria, para ver como as coisas se comportam de acordo com ela.

Hayek deixa clara sua posição com relação a sistemas complexos afirmando que

devemos nos livrar da simples superstição de que o mundo é tão organizado que é possível através de observação descobrir regularidades entre todos os fenômenos e que isto é uma suposição necessária para a aplicação de um método científico. O que já descobrimos sobre sistemas complexos até agora deve ser suficiente para nos mostrar que não devemos esperar isto. ([1964] 1967, p. 40)

Por fim, fica evidente então que o autor foco deste estudo se posiciona contrariamente ao racionalismo cartesiano com suas ideias de regras que possuem um elevado grau de abstração, ordens que também apresentam inúmeras vezes a impossibilidade de serem matematizadas, e complexidade interligando inúmeras regras e ordens de (quase) impossível formulação.

\footnotetext{
${ }^{9}$ Neste ponto este artigo contraria a tese de Kilpatrick (2001), acatando-a posteriormente no momento em que Arthur (1999) afirma que o governo deve atuar de modo a levar a economia para um estado estrutural que possa crescer e emergir naturalmente. Como uma mão indutora, rejeitando assim uma das proposições liberais de Hayek.
} 


\section{RACIONALISMO CONSTRUTIVISTA E COMPLEXIDADE NA ECONOMIA}

De posse das ideias de regras, ordens e complexidade, o estudo direciona-se agora para a aplicação daqueles conceitos no campo da economia sob a ótica estudada. Como já dito, Hayek faz uso de tais conceitos para defender o liberalismo, posicionando-se contra sistemas econômicos planificados, entretanto, pode-se notar também críticas que podem ser feitas utilizando tais ferramentas contra a racionalidade da microeconomia neoclássica fundamentalmente cartesiana observada, como por exemplo, na Teoria do Equilíbrio Geral Walrasiano.

Segundo Prado (2006), a microeconomia walrasiana (denominada por ele reducionista) possui como características principais: a análise de um sistema fechado, com agentes idênticos e isolados, perfeitos e racionais que não cometem erros e não precisam aprender, isolada da macroeconomia, entendendo o processo econômico não como um sistema em evolução suscetível a mudanças, mas como um sistema mecânico semelhante a um relógio. Prado (1994) ainda afirma, questionando seus pressupostos, que a racionalidade cartesiana é de propriedade do homem, o postula como ser egocêntrico, é capaz de lhe proporcionar os meios para que determinado objetivo seja alcançado, é objetivista, e encontra no pilar da utilidade uma forma de sustentar toda a sua teoria. Tais conceitos, como sabido, estão sendo amplamente questionados por correntes alternativas de pensamento, entretanto, como já exposto, a manutenção ou a queda do paradigma neoclássico em um futuro breve não é consenso dentro destas linhas de pensamento.

Ainda dentro da crítica ao racionalismo construtivista, ou à lógica cartesiana, Ganem (1996) apresenta argumentos a respeito das hipóteses utilizadas no modelo de equilíbrio geral walrasiano afirmando que as características de estabilidade introduzem ao modelo uma fundamental indeterminação, que as imperfeições de mercado amplamente conhecidas contribuem para a impossibilidade de construção de modelos que se pautam em princípios ou hipótese muito gerais, e que o relaxamento de hipótese no caminho de tornar os modelos mais realistas levam a resultados cada vez mais distantes do Ótimo de Pareto.

Arthur (1994), em um texto seminal da nova corrente de autores complexistas, critica as hipóteses a respeito do conhecimento na teoria econômica inspirada no racionalismo construtivista ao afirmar que a predição de certo agente depende do que ele espera que os outros irão fazer, e isto o agente em questão não sabe, destarte, o conhecimento não está disponível para todos.

Direcionando a análise para a crítica sobre a planificação feita por Hayek, observa-se mais uma vez que a escola cartesiana, como já visto, pregava a razão matemática como fundamental na explanação dos fenômenos. Nesta abordagem tal conceito pode também ser aplicado à microeconomia neoclássica, onde a racionalidade perfeita impera. Na planificação tem-se, portanto, um indivíduo sem restrições de sabedoria para operar o sistema econômico, sendo este o Estado, que seria capaz de fazer a alocação mais justa possível dos recursos. Esta seria uma das justificativas de implantação da planificação, a saber, se tudo pode ser planejado, 
então esta ação será executada pelo planejador central. Nas palavras do próprio Hayek,

é verdade que a tendência progressiva para um controle central de todos os processos sociais é o resultado inevitável de uma abordagem que insiste que tudo pode ser planejado e feito para mostrar uma ordem reconhecível, é verdade também que esta tendência tende a criar condições onde nada além de um governo central todo-poderoso será capaz de manter a ordem e a estabilidade. ([1946] 1948, p. 27)

Porém, Hayek (1935) critica tal postura afirmando que não existe um critério científico que permita a comparação entre a utilidade de diferentes bens para diferentes indivíduos, como seria então o Estado capaz de alocar da melhor forma os recursos?

Uma segunda crítica de Hayek à questão reside em outra explicação metodológica inerente a este sistema, o surgimento e crescimento da escola histórica em economia. Tem que ser dito que nas ciências naturais (ou seja, não nas sociais) existe a possibilidade de observar-se repetidas vezes determinado evento em idênticas condições. Nas ciências sociais experiências deste tipo são impossíveis (Hayek, 1935). A posição humana entre as ciências naturais e sociais (em uma como efeito e em outra como causa), implica que a explicação para fenômenos sociais é parte de experiências comuns. Ou seja, Hayek não acredita que os fenômenos econômicos presentes possam ser explicados com bases nos passados, o interstício entre um e outro gera diferenças que não podem ser ignoradas.

Sobre esta questão, ao atacar o pensamento histórico e sociológico, Hayek acaba se posicionando contra um dos fundamentos do método marxista. Entretanto, este posicionamento é até certo ponto contraditório (por mais estranho que possa parecer) pois, mesmo sendo uma doutrina que acabou gerando sistemas de cunho planificador, o marxismo é compatível com a complexidade, dado o método histórico que adota, e uma vez sabida a influência de Hegel em Marx. Como afirma Prado (2011), com base nos conceitos de quimismo, organismo e mecanismo, Hegel tratou o fenômeno natural como uma hierarquia composta por camadas cada vez mais complexas.

Neste ponto faz-se necessária uma explicação um pouco mais detalhada a respeito da influência supracitada de Hegel em Marx. Paulani (2000) afirma que, uma vez posicionado contra os opositores do componente histórico nos eventos, Marx, em a Crítica da Economia Política, direciona sua crítica a Hegel quando aquele rejeita assumir o social como natural, ou, de outro modo, defendendo que o concreto é o ponto de partida efetivo. A esquerda hegeliana via em Marx um idealismo quando este acreditava, ao contrário daqueles, que a filosofia não poderia oferecer soluções para o problema alemão. Ou seja, a influência de Hegel em Marx não era ilimitada.

Retornando à questão do peso histórico nos eventos, posteriormente a ideia de path dependence aplicada à economia industrial preconizada por Nelson e Win- 
ter (1982) vai contra às proposições de Hayek sobre o fator do impacto histórico nos eventos do presente.

Ainda sobre a questão da não existência da path dependence no campo da economia, Kilpatrick (2001) defende que os atuais complexistas rompem com esta suposição hayekiana ao julgarem que existe um lock in histórico que ocorre por causa da ação racional ${ }^{10}$ dos agentes. A aparente eficiência oriunda de retornos crescentes dinâmicos leva a uma real ineficiência de longo prazo. Ainda com Kilpatrick (2011), para os complexistas atuais a ação humana vale e os agentes são responsáveis pelos seus atos. Para eles uma força superior (ordem espontânea) pode levar a maus resultados que devem ser corrigidos. Indo assim de encontro com outra suposição de Hayek, a de que eventos aleatórios são mais eficientes que a ação coletiva.

A defesa do liberalismo econômico por Hayek vem então do fato de não concordar com o racionalismo cartesiano e do uso da abordagem histórica como explanação dos fenômenos presentes. Para ele o mercado seria o mecanismo capaz de alocar da forma mais justa possível os recursos dada a impossibilidade dos agentes possuírem conhecimento perfeito e, quanto ao método histórico, como já dito, mais uma vez, ele acredita que certos fenômenos apresentam um determinado grau de complexidade porque são formados por regras e ordens que simplesmente não podem ser explicados.

Nesta concepção, o problema de um sistema planificado como um método surge pelo fato de a autoridade responsável pela distribuição da riqueza ser também a detentora dos recursos. O problema é que uma autoridade terá que distribuir limitados recursos entre infinitos agentes ${ }^{11}$.

Com relação à microeconomia neoclássica ou ortodoxa, pode-se notar que a hipótese de atomismo sugerida por ela vai contra a ideia de complexidade desenvolvida por Hayek, na medida em que na complexidade as partes estão interligadas e dependem umas das outras, não é possível assim supor a independência dos agentes. $^{12}$

Podemos notar outra crítica de Hayek ([1964] 1967) contra esta abordagem na seguinte afirmação, ao propor que a formação de certas tendências, como por exemplo a teoria do Equilíbrio Geral Walrasiano, utilizam suposições muito gerais, tais como as ideias de que os agentes não são impedidos de entrar em um novo negócio do qual eles desejam fazer parte. Tais suposições determinam uma faixa de valores atingíveis pelas variáveis, mas não seus valores particulares. $\mathrm{Na}$ abordagem

\footnotetext{
${ }^{10}$ Não no sentido construtivista.

${ }^{11}$ Hayek não era a favor do anarquismo, para ele o governo deveria existir, mas apenas para garantir e estabelecer o limite de atuação e responsabilidade dos agentes.

12 Rotheim (1988), economista pós-keynesiano, traça um paralelo com as ideias hayekianas ao assumir a existência de um mundo orgânico no lugar de atômico, ou seja, onde as interações dos indivíduos são relevantes, as pessoas passam a adquirir conhecimento graças ao convívio, e este conhecimento deve ser levado em conta na hora da tomada de decisão.
} 
walrasiana, caso os agentes saibam os valores de todos os parâmetros eles poderão chegar aos preços e quantidades de equilíbrio, mas o fato é que o mercado é um fenômeno complexo e não um plano cartesiano onde os valores das variáveis podem ser consultados ao longo de um eixo, logo, de acordo com a visão alternativa tratada neste artigo, o conhecimento de todos os fatos para a determinação do preço e da quantidade não é adequado.

Com relação à introdução da abordagem cartesiana na microeconomia, atestando que a matematização não só é possível como também imprescindível, Hayek (1945) afirma que a abordagem matemática e o uso de equações simultâneas que adotam como uma de suas hipóteses o conhecimento perfeito, supondo que este conhecimento corresponde aos fatos relevantes da situação, foge do principal problema a ser respondido. O problema econômico na visão dele é a utilização de um conhecimento que nenhum indivíduo possui por completo.

Segundo Barbieri (2006), a respeito do cálculo socialista e do estudo da interação dos agentes, a teoria hayekiana postula que eles teriam de equacionar de maneira correta diversas características do problema econômico que lhes é proposto, e também as decisões que se espera que os outros agentes tomarão. Sabendo que estes outros agentes farão o mesmo tipo de "cálculo", este tipo de ação aumenta de maneira considerável a complexidade na coordenação. Continuando, a teoria considerada aqui conclui então que a análise econômica não pode prosseguir em bases tautológicas, uma vez que a capacidade cognitiva dos agentes é limitada, passando o conhecimento a ser meramente conjectural.

Do exposto no parágrafo anterior, a coordenação dos mercados deve ser estudada e explicada. Barbieri (2006) busca explicar esta coordenação com base na filosofia da ciência, ressaltando a importância do estudo do crescimento do conhecimento dos agentes para que se possa obter uma explicação satisfatória do funcionamento dos mercados. Em outras palavras, o autor afirma que para estudar os planos e ações dos agentes pode ser utilizada a teoria de crescimento do conhecimento.

Outra consideração a respeito da coordenação vem com Chaumont-Chancelier (1999), que defende que as regras explicam como a coordenação e a cooperação podem existir dentro de um número tão grande de agentes. Ainda de acordo com este autor, o problema lidado por Hayek busca explicar como surge a adesão por parte dos agentes às regras do grupo tomando como base o individualismo metodológico. A resposta vem por meio da análise e conceituação de regras que se aplicam a competição entre grupos, mas não dentro de grupos. Duas respostas são apresentadas, a primeira tem base na subordinação e hierarquia dentro de grupos e atesta que: supondo que para os agentes é melhor pertencer a um certo grupo do que não pertencer, fazendo com que eles se esforcem para se manter neste grupo, considerando que dentro dos grupos existe uma organização, e que talvez os agentes devam estar sujeitos a algum tipo de líder, a coordenação pode ser observada. A ignorância pode ser a segunda explicação para a questão de por que os agentes se sujeitam a regras. Nesta concepção, o homem beyekiano prefere ações com consequências minimamente previsíveis do que totalmente incertas. 
Vanberg (1986), baseado na teoria dos jogos, afirma que em um sistema de regras de cooperação deve existir um mecanismo que ofereça vantagens adicionais para os agentes que cooperam e desvantagens para os que não cooperam. Nesta linha, Hayek observa os agentes interconectados por relações, caso um deles não coopere, será lançado pelo grupo ao ostracismo ${ }^{13}$.

Hayek é contra o controle de preços, pela sua descrença no construtivismo, supõe que um indivíduo não é capaz de saber o melhor preço a ser praticado, indo na mesma linha, portanto, de sua crítica a respeito da alocação de recursos por parte do governo em regimes de planificação. $\mathrm{Na}$ abordagem da complexidade o sistema de preços deve ser utilizado para comunicar informação, sendo que os preços menos flexíveis implicam um sistema que cumpre sua função de maneira mais imperfeita. O feito mais significativo deste sistema é a economia do conhecimento com o qual opera, o quão pouco necessitam saber os indivíduos para poder fazer ações corretas, ou seja, os agentes não precisam ser oniscientes desde que os preços sejam flexíveis.

Finalizando, nesta seção pôde ser visto que Hayek faz críticas a duas distintas visões da economia, a planificação total e a microeconomia ortodoxa (ou neoclássica), sendo que ambas combinam no fato de se apoiar no racionalismo construtivista, que parece não ser concebível dentro da abordagem da economia e complexidade.

\section{CONCLUSÃO}

O presente trabalho buscou apresentar certos conceitos econômicos e filosóficos observados nos trabalhos de Friedrich August von Hayek. Supõe-se que tais conceitos possam servir de crítica ao racionalismo cartesiano, materializado neste estudo sob a forma da planificação e também sob as hipóteses da microeconomia neoclássica.

Primeiro foi apresentada a ideia do racionalismo cartesiano onde tudo é fruto de uma racionalidade perfeitamente formulada através da matemática. Posteriormente foi apresentado ao leitor o primeiro conceito para criticar o construtivismo, a saber, a ideia de regras, onde pôde-se notar a existência de certos eventos completamente impossíveis de serem descritos e menos ainda formulados. Para Chaumont-Chancelier (1999), estas regras podem explicar a coordenação dos agentes em um ambiente de difícil mapeamento como o é o sistema econômico. Em seguida veio a concepção a respeito de ordens de ações, que, assim como as regras, não oferecem oportunidade em inúmeros casos para uma formalização matemática. De posse destes dois conceitos a complexidade é introduzida, um sistema onde uma

\footnotetext{
${ }^{13}$ Uma visão institucionalista sobre coordenação pode ser obtida em Olson (1971 [1965]) e Ostrom (1990).
} 
intrincada rede de relações torna qualquer forma de teorização formal impossível, aparecendo geralmente em fenômenos sociais.

Sobre sistemas complexos foi exposto que uma certa ordem resultante não é apenas a soma de eventos individuais, existe uma conexão entre as partes que não pode ser ignorada. As características deste tipo de sistema para Prado (2006) são: integração em uma dinâmica não linear operante fora do equilíbrio, uso da racionalidade limitada e a existência de vínculos dados por instituições e estruturas sociais.

Quando os conceitos de regras, ordens e complexidade são aplicados ao campo da ciência econômica, nota-se que o planejamento central se faz impossível, pela impossibilidade da aplicação do racionalismo construtivista em uma ciência social como é a economia. Nesta abordagem, seria impossível a existência de um agente com total sabedoria operando todo o sistema econômico, realizando a melhor e mais eficiente alocação de recursos entre os indivíduos.

Uma segunda teoria criticada pelos opositores do racionalismo cartesiano é a microeconomia ortodoxa com as suas hipóteses de racionalidade perfeita e atomismo. Dada a impossibilidade de formular manual ou intencionalmente regras e ordens, a racionalidade cartesiana não pode ser aplicada, e graças a conexão apresentada pelos agentes em um sistema complexo, o atomismo nesta concepção passa a ser também uma hipótese de difícil implantação. Dentro desta crítica, Arthur (1994) afirma que a predição de certo agente depende do que ele espera que os outros irão fazer, e isto o agente em questão não tem como saber, destarte, o conhecimento não está disponível para todos. Barbieri (2001) admite que a análise econômica não deve residir em axiomas irrefutáveis, e que estes devem variar quando se variam as suposições a respeito do conhecimento dos agentes. Ganem (1996) ataca o modelo do Equilíbrio Geral Walrasiano atentando para sua indeterminação e para a impossibilidade de uma abordagem geral a respeito do assunto.

Sendo assim, nesta abordagem da economia e complexidade a maior questão na elaboração das respostas aos problemas vem da necessidade de averiguar um sem-número de dados que possuem características que os diferenciam uns dos outros.

Conclui-se, portanto, que Hayek (guardadas as devidas críticas já apresentadas) posicionando-se contra o racionalismo cartesiano e a favor da complexidade chega a resultados onde o liberalismo é a melhor forma para alocar recursos, e também na defesa de um sistema de preços flexíveis, dada a ausência de total conhecimento dos agentes.

Sobre o debate atual, entre a microeconomia neoclássica e a economia e complexidade, a conclusão à qual este trabalho chega é que os estudiosos do Instituto Santa Fé, liderados por Brian Arthur, fazendo amplo uso da abordagem computacional, defendem uma nova metodologia para a análise econômica, que trate cada estudo de forma única, rompendo assim com hipóteses gerais e simplificadoras que permeiam toda a microeconomia walrasiana. Nota-se então, com o que fora aqui exposto, que pode se supor a existência de uma relação entre a crítica original hayekiana e os atuais estudos da complexidade. 


\section{REFERÊNCIAS BIBLIOGRÁFICAS}

ANGELI, Eduardo (2007) Hayek e a teoria das instituições. Dissertação (Mestrado em Economia) Instituto de Economia, Universidade Estadual de Campinas, Campinas.

ARTHUR, Brian (2005) “Out-of-equilibrium economics and agent-based modeling”. In Tesfatsion, L.; Judd, K. L. (orgs.). Handbook of computational economics volume 2: agent-based computational economics. 1. ed. North-Holland, p. 1551-1564.

. (1999) "Complexity and the economy." Science, v. 2, n.284, p. 107-109.

(1994) "Inductive reasoning and bounded rationality: the el farol problem". American Economic Review, v. 84, n. 2, p. 406-411.

BARBIERI, Fabio (2006) "Filosofia da ciência como ferramenta microeconômica” Nova Economia, v. 16, n. 3 p. $507-534$.

- (2001) O processo de mercado na escola austríaca moderna. Dissertação (Mestrado em Economia) — Faculdade de Economia Administração e Contabilidade, Universidade de São Paulo, São Paulo.

BENTHAM, Jeremy ([1781] 1988) An Introduction to the Principles of Morals and Legislation. 1. ed., London: British Library.

CHAUMONT-CHANCELIER, Frédérique (1999) “Hayek's complexity” Journal des Economistes et des Etudes Humaines, v. 9, n. 4, p. 543-564.

DAVIDSON, Paul (1988) "A technical definition of uncertainty and the long-run non-neutrality of money" Cambridge Journal of Economics, v. 12, n.3, p. 329-337.

EPSTEIN, Joshua M. (2006) “Equilibrium, explanation and Gauss's tombstone”. In Epstein, J. (org.). Generative social science: studies in agent-based computational modeling. Princeton: Princeton University Press, p. 72-74.

; HAMMOND, Ross A. (2006) "Non-Explanatory equilibria: an extremely simple game with (mostly) unattainable fixed points". In Epstein, J. (org.). Generative social science: studies in agent-based computational modeling. Princeton: Princeton University Press. p. 75-85.

FOLEY, Duncan (2007) Unholy trinity: labor capital and land in the new economy. London: Taylor and Francis.

GANEM, Ângela (2012) “O mercado como ordem social em Adam Smith, Walras e Hayek”, Economia e Sociedade, v. 21, n. 1, p. 143-164.

(2006) "Regras e ordem do mercado nas visões de Adam Smith e F. A. Hayek", Endoxa, v.21, p. 295-312.

(1996) "Demonstrar a ordem racional do mercado: reflexões em torno de um projeto impossível”, Revista de Economia Política, v. 16, n. 2, p. 105-122.

HAHN, Frank (1991) “The next hundred years”, The Economic Journal, v. 101, n. 404, p. 47-50.

HAYEK, Friedrich A. von ([1973] 1985) "Direito, legislação e liberdade: uma nova formulação dos princípios liberais de justiça e economia política” São Paulo: Visão.

(1967) "Notes on the evolution of systems of rules of conduct: the interplay between rules of individual conduct and the social order of actions". In Hayek, F. Studies in philosophy, politics and economics. Chicago: The University of Chicago Press, p. 66-81.

([1964] 1967) "The theory of complex phenomena". In Hayek, F. Studies in philosophy, politics and economics. Chicago: The University of Chicago Press, p. 22-42.

([1963] 1967) "Rules, perception and intelligibility" In Hayek, F. Studies in philosophy, politics and economics. Chicago: The University of Chicago Press, p. 43-65.

([1946] 1948) Individualism: true and false”. In Hayek, F. Individualism and Economic Order. South Bend: Gateway Editions, p. 1-32.

(1945) "The use of knowledge in society" American Economic Review, v.35, n.4, p. 519-530.

(1935) "The nature and history of the problem". In Hayek, F. Collectivist economic planning:

Critical Studies on the Possibilities of Socialism. New York: Augustus M. Kelley.

KILPATRICK, Henry E. Jr. (2001) “Complexity, spontaneous order, and Friedrich Hayek: are spontaneous order and complexity essentially the same thing?” Complexity, v. 6, n. 4, p. 16-20. 
MAS-COLELL, Andreu; WHINSTON, Michael D.; GREEN, Jerry R. (1995) Microeconomic Theory. Oxford: Oxford University Press.

MISES, Ludwig. Von (1949) Ação Humana: Um Tratado de Economia. Rio de Janeiro: Instituto Liberal.

NELSON, Richard B.; WINTER, Sidney G. (1982) An Evolutionary Theory of Economic Change. Harvard: Harvard University Press.

OLSON, Mancur ([1965] 1971) The Logic of Collective Action: Public Goods and the Theory of Groups. Cambridge: Harvard University Press.

OSTROM, Elinor (1990) Governing the Commons: The Evolution of Institutions for Collective Action. Cambridge: Cambridge University Press.

PAULANI, Leda M. (2010) "Ciência econômica e modelos de explicação científica: retomando a questão”. Revista de Economia Política, v. 30, n.1, p. 27-44.

(2000) “A atualidade da crítica da economia política”, Crítica Marxista, v. 10, p. 111-121.

(1999) "Neoliberalismo e individualism”. Economia e Sociedade, v. 13, p. 115-127.

(1996) "Hayek e o individualismo no discurso econômico". Lua Nova, v. 38, p. 97-124.

PRADO, Eleutério F. S. (2011) Complexidade e Práxis. São Paulo: Plêiade. (2008) "A dialética de Marx e o evolucionismo de Hayek", Revista da Sociedade Brasileira de Economia Política, v. 23, p. 26-47.

(2006) “Microeconomia reducionista e microeconomia sistêmica”, Nova Economia, v. 16, n. 2, p. 303-322. (2001) “A ortodoxia neoclássica”, Estudos Avançados, v. 15, n. 41, p. 9-20. (1994) “A constelação pós-walrasiana”, Revista de Economia Política, v. 14, n. 4, p. 110-117.

ROTHEIM, Roy. J. (1988) "Keynes and the language of probability and uncertainty", Journal of Post Keynesian Economics, v. XI, n. 1, p. 82-99.

SHEPSLE, Kenneth A. (2010) Analyzing Politics: Rationality, Behavior, and Institutions. 2. ed. Norton.

VANBERG, Viktor (1986) "Spontaneous market order and social rules: a critical examination of F. A. Hayek theory of cultural evolution", Economics and Philosophy, v. 2, n. 1, p. 75-100.

VAUGHN, Karen I. (1999) "Hayek's theory of the market order as an instance of the theory of complex, adaptive systems", Journal des Economistes et des Etudes Humaines, v. 9, n. 2-3, p. 241-256. 